\title{
A Comparative Physiochemical Properties of Esomeprazole Brands
}

\author{
Safila Naveed, Fatima Qamar \\ Faculty of Pharmacy, Jinnah University for Women, Karachi, Pakistan \\ Email: safila117@yahoo.com
}

Received 5 July 2014; revised 9 August 2014; accepted 10 September 2014

Copyright (C) 2014 by authors and OALib.

This work is licensed under the Creative Commons Attribution International License (CC BY). http://creativecommons.org/licenses/by/4.0/

(c) (i) Open Access

\section{Abstract}

Esomeprazole is the S-isomer of Omeprazole and it is a proton pump inhibitor (PPI). Esomeprazole is used in acid-related disorders and it is available as several brands in the market which makes it difficult for doctors to select the effective, safe and economic one for patients. Therefore we have decided to establish pharmaceutical equivalence among the different brands of esomeprazole available in Karachi, Pakistan. In our present study different brands of esomeprazole are evaluated for weight variation, hardness and dissolution. Disintegration Test shows results for NEX 01, ESS 02, EZI 03 and they disintegrate in 1.35, 1.15 and 2.15 minutes respectively. Dissolution test demonstrate the result as NEX 01, ESS 02, EZI 03 is $100.00 \%$ for NEX, $117.87 \%$ for ESS and $\mathbf{8 0 . 6 6 \%}$. The results showed that all parameters weight-variation, hardness, dissolution of different brands of esomeprazole are in accordance with the USP limits.

\section{Keywords}

Esomeprazole, Thickness, Weight Variation, Hardness, Friability

Subject Areas: Analytical Chemistry, Information Science, Public Health

\section{Introduction}

Omeprazole is a proton pump inhibitor (PPI). It is a substituted benzimidazole and exists as a racemic mixture of the S- and R-isomers. Esomeprazole (Figure 1) is the S-isomer of Omeprazole. It is the first (PPI) developed as an optical isomer and is used for the treatment of acid-related disorders. Esomeporazole has shown a similar mechanism of action to Omeprazole. It is also an effective inhibitor of gastric acid secretion [1]. However it differs from Omeprazole, as it is less prone to first-pass metabolism [2]. It also shows slower plasma clearance and results in higher plasma concentrations [3]. This leads to a more effective and long-lasting gastric acid secretion inhibition effect over 24-h dose interval. Moreover Esomeprazole shows less inter individual variations therefore it might show consistent response [2]. A recent study has showed that esomeprazole at a dose of $40 \mathrm{mg}$ 


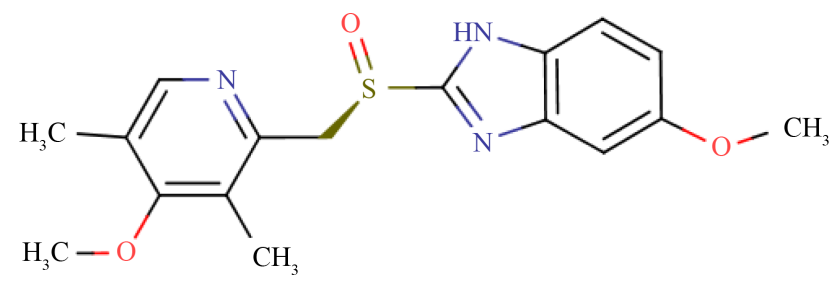

Figure 1. Structure of Esomeprazole.

once daily shows more effective gastric acid control at steady state than $40 \mathrm{mg}$ doses of lansoprazole, rabeprazole and pantoprazole, in patients with symptomatic gastro esophageal reflux disease (GERD [4] [5]. It also shows a higher healing rate for erosive esophagitis and provides a long relief of heartburn in more patients than any other available PPI [6].

Esomeprazole is a competitive inhibitor of the enzymes CYP2C9 and CYP2C19. It may interact with drugs that depend on these enzymes for metabolism, for example warfarin and diazepam; their concentrations may increase if used concomitantly with esomeprazole. Some drugs depend on stomach $\mathrm{pH}$ for their absorption and interact with omeprazol. Ketoconazole or atazanavir drugs like drugs that depend on an acidic environment will be hardly absorbed and those drugs that are broken down in acidic environments example erythromycin will be absorbed efficiently than normal [7].

PPI may be associated with a greater risk of Clostridium difficile-associated diarrhea and hip fractures [8]. By suppressing acid-mediated proteins breakdown, esomeprazole leads to an elevated risk of developing drug and food allergies. This happens due to undigested proteins then passing into the GI tract where sensitization occurs. It is however unknown whether this risk occurs with long-term use or with short-term use [9]. Patients are frequently administered esomeprazole in intensive care as a protective measure against ulcers. This use is also related with a percent increase in occurrence of pneumonia [10]. We have done these types of study on different drugs which is very useful for selection of drug for pharmacist and doctors [11]-[13].

\section{Methodology}

We have purchased different brands of Esomeprazole capsules (USP) of $20 \mathrm{mg}$ from the local market i.e. NEXUM (NEX), ESSO (ESS) and EZIUM (EZI). Physicochemical tests were performed for the comparison of different brands.

\subsection{Weight Variation Test}

Weight Variation test indicates content uniformity of each dosage form during compression. For this 10 capsules of each brand were weighed on Electronic Balance FX-400 and determined that weight of each capsule must be within BP/USP limits i.e. for capsules containing less than $300 \mathrm{mg}$ not more than 2 capsules out of the sample may be outside $\pm 10 \%$ of the average and all must be within $20 \%$.

\subsection{Disintegration Test}

Disintegration apparatus (Curro model no DS-0702) was used to perform disintegration test. Six capsules were placed in the basket and then covered with the disk. Temperature is maintained at $35^{\circ} \mathrm{C}$ to $39^{\circ} \mathrm{C}$ using water or another liquid (unless specified) as the immersion fluid. After a specified time examine whether all the capsules have been disintegrated completely. If 1 or 2 capsules do not disintegrate, the test is repeated on 12 capsules. Out of 18 capsules 16 tested are disintegrated the requirements is met. Follow the same procedure for each brand. According to USP, capsule should disintegrate in not more than 30 minutes.

\subsection{Dissolution Test}

We perform this test on GDT-7L of Galvano Scientific dissolution apparatus. For this we take $900 \mathrm{ml}$ of water in the vessel, assemble the equipment and maintained at temperature $37^{\circ} \mathrm{C} \pm 0.5^{\circ} \mathrm{C}$. Put one capsule of each brand of Esomeprazole in a dry basket. Lower the basket into position before rotation, start rotation of the basket at 50 RPM. Withdraw a sample of ten $\mathrm{ml}$ at 15, 30, 45 and $60 \mathrm{~min}$ intervals from each vessel, sample must be taken from a zone midway between the surface of the dissolution medium and the top of the rotating basket, not 
less than $10 \mathrm{~mm}$ below the surface and at least $10 \mathrm{~mm}$ from the vessel wall. Determine the quantity of esomeprazole dissolved as specified in USP.

\section{Results}

The physicochemical parameters of different brands of esomeprazole capsules (NEX 01, ESS 02, and EZI 03) were analyzed. The results of average weight of 10 capsules of NEX 01, ESS 02, EZI 03 is $136.9 \mathrm{mg}, 138.5 \mathrm{mg}$, $135.9 \mathrm{mg}$ and their upper \& lower limits are 148.07 - 125.2, 143.3 - 128.2, 152.4 - 124.5 respectively which is show in Table 1 and Table 2. Disintegration Test shows following results for NEX 01, ESS 02, EZI 03 and they disintegrate in 1.35, 1.15 and 2.15 minutes respectively shown in Table 4. Dissolution test demonstrate the result as NEX 01, ESS 02, EZI 03 is 100.00\% for NEX, 117.87\% for ESS and 80.66\% shown in Table 5.

\section{Discussion}

The aim of this study is to evaluate and compare the quality standards of three brands of esomeprazole capsules (NEX 01, ESS 02, EZI 03) commercially available in Karachi, Pakistan. For comparatively study, physicochemical testing such as weight variation, in-vitro dissolution and disintegration of esomeprazole capsules (20 mg) (NEX 01, ESS 02, EZI 03) were performed and evaluated. Dissolution, disintegration and Uniformity of weight are compendial standards to checks the quality of capsules. The weight variation values of NEX 01, ESS 02, EZI 03 are given in Table 1, which shows that ESS 02 has the highest value of mean weight among all the three brands. According to USP the requirements of weight variation are met when out of 20 capsules of each brand the weight of not more than 2 capsules differs from the average weight by more than $10 \%$ (Table 3). Dif-

Table 1. Statistical weight variation table.

\begin{tabular}{ccccc}
\hline Serial no. & Average weight $(\mathrm{mg})$ & Standard deviation $(\mathrm{mg})$ & Upper Limit $(\mathrm{X}+3 \mathrm{~S})$ & Lower Limit $(\mathrm{X}-3 \mathrm{~S})$ \\
\hline NEX 01 & 136.9 & 3.7252 & 148.07 & 125.72 \\
ESS 02 & 138.5 & 2.558 & 143.5 & 128.2 \\
EZI 03 & 135.9 & 4.648 & 152.4 & 124.5 \\
\hline
\end{tabular}

Table 2. Calculation for weight variation test.

\begin{tabular}{ccccccccccc}
\hline NEX & CAP1 & CAP2 & CAP3 & CAP4 & CAP5 & CAP6 & CAP7 & CAP8 & CAP9 & CAP10 \\
\hline WEIGHT & 132 & 138 & 130 & 140 & 136 & 138 & 138 & 136 & 138 & 143 \\
MEAN & 136.9 & 136.9 & 136.9 & 136.9 & 136.9 & 136.9 & 136.9 & 136.9 & 136.9 & 136.9 \\
SD & 3.7252 & 3.7252 & 3.7252 & 3.7252 & 3.7252 & 3.7252 & 3.7252 & 3.7252 & 3.7252 & 3.7252 \\
UCL & 148.07 & 148.07 & 148.07 & 148.07 & 148.07 & 148.07 & 148.07 & 148.07 & 148.07 & 148.07 \\
LCL & 125.72 & 125.72 & 125.72 & 125.72 & 125.72 & 125.72 & 125.72 & 125.72 & 125.72 & 125.72 \\
COMMENT & OK & OK & OK & OK & OK & OK & OK & OK & OK & OK \\
ESS & CAP1 & CAP2 & CAP3 & CAP4 & CAP5 & CAP6 & CAP7 & CAP8 & CAP9 & CAP10 \\
WEIGHT & 138 & 138 & 141 & 141 & 135 & 138 & 132 & 133 & 141 & 148 \\
MEAN & 138.5 & 138.5 & 138.5 & 138.5 & 138.5 & 138.5 & 138.5 & 138.5 & 138.5 & 138.5 \\
SD & 4.648 & 4.648 & 4.648 & 4.648 & 4.648 & 4.648 & 4.648 & 4.648 & 4.648 & 4.648 \\
UCL & 152.4 & 152.4 & 152.4 & 152.4 & 152.4 & 152.4 & 152.4 & 152.4 & 152.4 & 152.4 \\
LCL & 124.5 & 124.5 & 124.5 & 124.5 & 124.5 & 124.5 & 124.5 & 124.5 & 124.5 & 124.5 \\
COMMENT & OK & OK & OK & OK & OK & OK & OK & OK & OK & OK \\
EZI & CAP1 & CAP2 & CAP3 & CAP4 & CAP5 & CAP6 & CAP7 & CAP8 & CAP9 & CAP10 \\
WEIGHT & 133 & 133 & 137 & 138 & 140 & 139 & 136 & 135 & 133 & 135 \\
MEAN & 135.9 & 135.9 & 135.9 & 135.9 & 135.9 & 135.9 & 135.9 & 135.9 & 135.9 & 135.9 \\
SD & 2.558 & 2.558 & 2.558 & 2.558 & 2.558 & 2.558 & 2.558 & 2.558 & 2.558 & 2.558 \\
UCL & 143.5 & 143.5 & 143.5 & 143.5 & 143.5 & 143.5 & 143.5 & 143.5 & 143.5 & 143.5 \\
LCL & 128.2 & 128.2 & 128.2 & 128.2 & 128.2 & 128.2 & 128.2 & 128.2 & 128.2 & 128.2 \\
COMMENT & OK & OK & OK & OK & OK & OK & OK & OK & OK & OK \\
\hline & & & & & & & & & &
\end{tabular}


Table 3. Weight variation test.

\begin{tabular}{cccc}
\hline Serial no & Result $(\mathrm{mg})$ & USP specification & Deviation from USP \\
NEX 01 & 136.9 & $\pm 10 \%$ & $\pm 10 \%$ \\
ESS 02 & 138.5 & $\pm 10 \%$ & Pass \\
EZI 03 & 135.9 & Pass & \\
\hline
\end{tabular}

Table 4. Disintegration test.

\begin{tabular}{cccc}
\hline Serial No. & Disintegration time (min) & Limits & Deviation from USP \\
NEX 01 & 1.35 & NMT 15 Min & PASS \\
ESS 02 & 1.15 & NMT 15 Min & PASS \\
EZI 03 & 2.15 & NMT 15 Min & PASS \\
\hline
\end{tabular}

Table 5. Dissolution test.

\begin{tabular}{|c|c|c|c|}
\hline Serial No. & Dissolution at $30 \mathrm{~min}$ & USP Spec & Deviation from USP \\
\hline NEX 01 & $100.00 \%$ & & pass \\
\hline ESS 02 & $117.87 \%$ & $\begin{array}{c}\text { Not less than } 80 \%(\mathrm{Q}) \text { of the labeled amount } \\
\text { dissolved in } 60 \mathrm{~min}\end{array}$ & pass \\
\hline EZI 03 & $80.66 \%$ & & pass \\
\hline
\end{tabular}

ference in weight between these 3 brands (NEX 01, ESS 02, EZI 03) of esomeprazole capsules is due to the non-uniform amount of an API. Disintegration Test shows following results for NEX 01, ESS 02, EZI 03 and they disintegrate in 1.35, 1.15 and 2.15 minutes respectively shown in Table 4. Dissolution test demonstrate the result as NEX 01, ESS 02, EZI 03 is $100.00 \%$ for NEX, 117.87\% for ESS and 80.66\% shown in Table 5.

These types of comparative studies are very useful for doctors, pharmacist and prescriber because by these studies they can analyze which is the better choice of all brands [14]-[22].

\section{Conclusion}

It is concluded that the results of all the tests (weight variation, disintegration and dissolution) of selected brands of esomeprazole capsules (20 mg) exhibit some difference but these variations are in specified limits.

\section{References}

[1] Anderson, T., Röhss, K., Hassan-Alin, M. and Bredberg, E. (2000) Pharmacokinetics and Dose-Response Relationship of Esomeprazole (Abstract). Gastroenterology, 118, A1210.

[2] Lind, T., Rydberg, L., Kylebäck, A., et al. (2000) Esomeprazole Provides Improved Acid Control versus Omeprazole in Patients with Symptoms of Gastro-Oesophageal Reflux Disease. Alimentary Pharmacology Therapeutics, 14, 861867. http://dx.doi.org/10.1046/j.1365-2036.2000.00813.x

[3] Hassan-Alin, M., Röhss, K., Anderson, T. and Nyman, L. (2000) Pharmacokinetics of Esomeprazole after Oral and Intravenous Administration of Single and Repeated Doses to Healthy Subjects (Abstract). Gastroenterology, 118, A16. http://dx.doi.org/10.1016/S0016-5085(00)82133-2

[4] Miner Jr., P., Katz, P.O., Chen, Y. and Sostek, M. (2003) Gastric Acid Control with Esomeprazole, Lansoprazole, Omeprazole, Pantoprazole, and Rabeprazole: A Five-Way Crossover Study. The American Journal of Gastroenterology, 98, 2616-2620. http://dx.doi.org/10.1111/j.1572-0241.2003.08783.x

[5] Miner Jr., P., Katz, P.O., Chen, Y. and Sostek, M. (2006) Reanalysis of Intragastric pH Results Based on Updated Correction Factors for Slimline and Zinetics 24 Single-Use pH Catheters. The American Journal of Gastroenterologyv, 101, 404-405; Author Reply, 405-406. http://dx.doi.org/10.1111/j.1572-0241.2006.00401_3.x

[6] Edwards, S.J., Lind, T. and Lundell, L. (2006) Systematic Review: Proton Pump Inhibitors (PPIs) for the Healing of Reflux Oesophagitis-A Comparison of Esomeprazole with Other PPIs. Alimentary Pharmacology Therapeutics, 24, 743-750. http://dx.doi.org/10.1111/j.1365-2036.2006.03074.x

[7] Stedman, C.A. and Barclay, M.L. (2000) Review Article: Comparison of the Pharmacokinetics, Acid Suppression and 
Efficacy of Proton Pump Inhibitors. Alimentary Pharmacology Therapeutics, 14, 963-978. http://dx.doi.org/10.1046/j.1365-2036.2000.00788.x

[8] Yang, Y.X., Lewis, J.D., Epstein, S. and Metz, D.C. (2006) Long-Term Proton Pump Inhibitor Therapy and Risk of Hip Fracture. The Journal of the American Medical Association, 296, 2947-2953. http://dx.doi.org/10.1001/jama.296.24.2947

[9] Pali-Schöll, I. and Jensen-Jarolim, E. (2011) Anti-Acid Medication as a Risk Factor for Food Allergy. Allergy, 66, 469-477. http://dx.doi.org/10.1111/j.1398-9995.2010.02511.x

[10] Herzig, S.J., Howell, M.D., Ngo, L.H. and Marcantonio, E.R. (2009) Acid-Suppressive Medication Use and the Risk for Hospital-Acquired Pneumonia. The Journal of the American Medical Association, 301, 2120-2128. http://dx.doi.org/10.1001/jama.2009.722

[11] Huma, D., Safila, N. and Asma, R. (2014) Comparative Study of Four Different Brands of Acetaminophen Available in Karachi. World Journal of Plastic Surgery, 2, 586-590.

[12] Huma, D., Safila, N. and Nimra, W. (2014) Comparative Study of Four Different Brands of Captopril Available in Karachi. International Research Journal of Pharmacy, 5, 374-377.

[13] Huma, D. and Safila, N. (2014) Manufacturing of New Formulations of Isosorbide Mononitrate by Dry Granulation Method and Their Comparative Evaluation with Brands Available in the Market. International Research Journal of Pharmacy, 5, 168-171.

[14] Naveed, S. and Qamar, F. (2014) Comparative Analysis of Different Brands of Diclofenac Sodium. MJPMS: Mintage Journal of Medical and Pharmaceutical Sciences, 3, 38-40.

[15] Naveed, S., Naseem, Y., Samie, S., Khan, S. and Ramzan, S. (2014) Degradation Study of Five Different Brands of Ciprofloxacin Using UV-Visible Spectrophotometer and Their Comparative Study. International Research Journal of Pharmacy, 5, 189-190. http://www.irjponline.com/admin/php/uploads/2130_pdf.pdf

[16] Naveed, S. and Qamar, F. (2014) Comparative Study of Different Brands of Alprazolam. Global Journal of Medical Research, 14, 25-28. https://globaljournals.org/GJMR_Volume14/5-Comparative-Study-of-Different-Brands.pdf

[17] Naveed, S. and Waheed, N. (2014) Comparative Study of Three Different Brands of Doxycycline Capsules Available in Karachi. Open Access Library Journal, 1, 1-7. http://dx.doi.org/10.4236/oalib.1100458 http://www.oalib.com/paper/3052751\#.U5GpAXKSytk

[18] Naveed, S. and Qamar, F. (2014) Comparative Study of Metronidazole Formulations. DHR International Journal of Pharmaceutical Sciences (DHR-IJPS), 5, 111-116.

[19] Naveed, S., Dilshad, H. and Aziz, S. (2014) Comparative Study of Different Brands of Atenolol Available In Karachi. MJPMS: Mintage Journal of Medical and Pharmaceutical Sciences, 3, 17-19.

[20] Naveed, S., Qamar, H., Jawaid, W. and Bokhari, U. (2014) Effect of Acid, Base and Time on Different Brands of Glimepiride, Open Access Library Journal, 1, 1-5. http://www.oalib.com/paper/3099379

[21] Naveed, S. and Nawab, A. (2014) Assay of LVFX (Levofloxacin) in Different Formulation by UV Spectroscopy. International Journal of Pharmaceutical Research \& Drug Development, 1, 13-16.

[22] Dilshad, H., Naveed, S. and Ahad, S. (2014) Comparative Study of Different Brands of Tizanidine. International Journal of Pharmaceutical Research \& Drug Development, 1, 1-8. 